WiCHITA STATE

UNIVERSITY

\title{
Performance Evaluations
}




\section{Performance Evaluations}

Human Resources administers performance evaluations for all staff. Procedures are different for evaluating University Support Staff, Unclassified Professionals, Faculty, and student employees.

- University Support Staff Performance Evaluations

- Unclassified Professionals Performance Evaluations

- Faculty Performance Evaluations

- Student Employee Performance Evaluations

Send URL

http://webs.wichita.edu/?u=humanresources $2 \& \mathrm{p}=/$ employee relations/performance evaluation/perfo rmance evaluations/ 


\section{eses Wichita State \\ Uौ UNIVERSITY}

A-Z Index

Directories

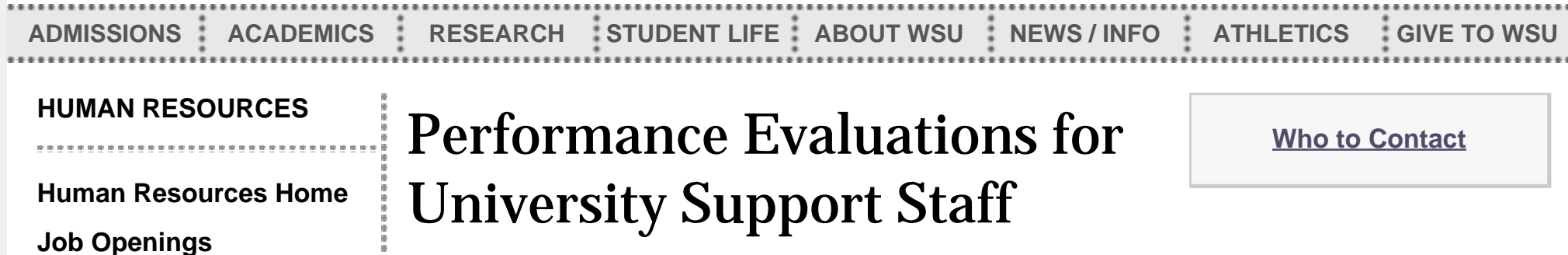

\section{Job Openings}

Hiring Process

Training

\section{Benefits}

Employee Relations

Timekeeping

Policies

Forms

\section{Contact Us}

\section{IN THE NEWS}

\section{USS to UP \\ Reclassification}

\section{Video of Market Study Campus Visit}

\section{Financial Counseling}

Office of Human Resources

1845 Fairmount

Box 15

Wichita, KS 67260-0015

316-978-3065

\begin{abstract}
The Performance Management Process is used to assess how an employee performs his or her job duties, identify performance expectations based on his or her position description and provide feedback to the employee on four essential components of the performance management process: Performance Planning, Coaching and Feedback, Reviewing and Appraising Performance, Recognizing and Rewarding Performance.

To help employees achieve and exceed performance expectations it is crucial for supervisors to have a current position description on file and to complete a performance appraisal.
\end{abstract}

Note: The current cycle begins March 1, 2016 and ends February 28, 2017 and will be completed in myPerformance. All 3 phases in the current cycle (planning, mid-year, and end-of-year) must be completed by February 28, 2017. Please refer to the myPerformance website for 2016 evaluations beginning on or after March 1.

\section{Forms}

Please refer to the myPerformance website for USS evaluations beginning on or after March 1 , 2016.

Supervisors of University Support Staff were following the Performance Management Process outlined by the State of Kansas and will no longer use this process for new evaluations. If you still need access online, you must login to Classified Evaluation and Development System (CEEDS).

\section{Training}

- There are two levels of training available for this evaluation: myPerformance Training and Managing Employee Performance. Read more about how to sign up for training.

- Matthew Johnston or Frankie Kirkendoll are available to answer questions.

- If you have difficulties signing into your performance evaluation, please contact Joan Antes.

\section{Annual Evaluations}

Note: The following dates apply to the 2015-2016 evaluation cycle that was used in CEEDS. A University Support Staff's (USS) evaluation should be reviewed from March 1 to the last day of February each year, unless that employee is a new hire (probationary) or on a special evaluation.

There are three phases that must take place during a review period: The Performance Planning Phase, the Mid-Review Phase, and the End-of-Review Phase. Several, regularly scheduled meetings should occur between the supervisor and employee throughout the evaluation cycle, and three of these particular meetings should focus solely on these phases.

1. The Performance Planning Phase should be completed within the first 30 days of the cycle (between March 1 - 31) to set objectives and expectations for the employee and 
collect the employee's signature on those objectives.

2. The Mid-Review Phase should be completed between mid-August and mid-September to discuss the employee's progress towards the objectives, the need to amend any of the objectives, and to collect the employee's signature for the amended evaluation.

3. The End-of-Review Phase should be completed and submitted to Human Resources on or before the last day of February. This includes sending a signed copy of the full evaluation to Campus Box \#15 by the end of the review period. The signed copy should include signatures from all 3 phases described above.

\section{Probationary Evaluations}

Each newly hired USS completes a six-month probationary period. The evaluation cycle is therefore reduced. When the probationary period is close to ending, the supervisor can either extend the probationary period for six additional months or recommend permanent status. If the supervisor fails to complete the evaluation on time, the employee will automatically switch to permanent status.

- The Performance Planning Phase should be completed during the first month of employment to set objectives and expectations for the employee and collect the employee's signature on those objectives.

- The Mid-Review Phase should be completed during the third month of employment to discuss the employee's progress towards the objectives, the need to amend any of the objectives, and to collect the employee's signature for the amended evaluation.

- The End-of-Review Phase should be completed and submitted to Human Resources no later than the six-month deadline. This includes sending a copy of the full evaluation to Campus Box \#15 by the end of the review period. The signed copy should include signatures from all 3 phases described above. If this does not occur, the employee will automatically be placed into permanent status.

If the Overall Rating on the evaluation is Needs Improvement or Unsatisfactory, a Special Evaluation is recommended (see Special Evaluations below), with extension of the probationary period.

- Once the probationary period is completed, an employee may need to be placed onto a Special Evaluation (see below) in order to coincide with the annual evaluation cycle that will begin March 1. (For example, if an employee is hired on June 1, their 6 month probationary period would end on December 31. Beginning January 1, that employee will need to be put on a Special Evaluation until the last day of February to coincide with the annual evaluation cycle beginning March 1.)

\section{Special Evaluations}

Special Evaluations are any other evaluation other than a 12-month duration on the annual cycle. This evaluation type can be used for several situations, but the most common are for getting an employee onto the annual evaluation cycle after their probationary period, transferring employees, and for unsatisfactory performance.

If a supervisor is needing a Special Evaluation to simply coincide with the annual cycle or for a transferring employee, contact joan.antes@wichita.edu to get a new form set up in the CEEDS software.

If a supervisor is needing a Special Evaluation for unsatisfactory performance, more steps need to be taken. Please review Discipline and Corrective Action for more information.

\section{Who to contact:}

Matthew Johnston

Associate Director

(316) 978-6123

To make an appointment, please contact LaMar Brown at (316) 978-3068. 


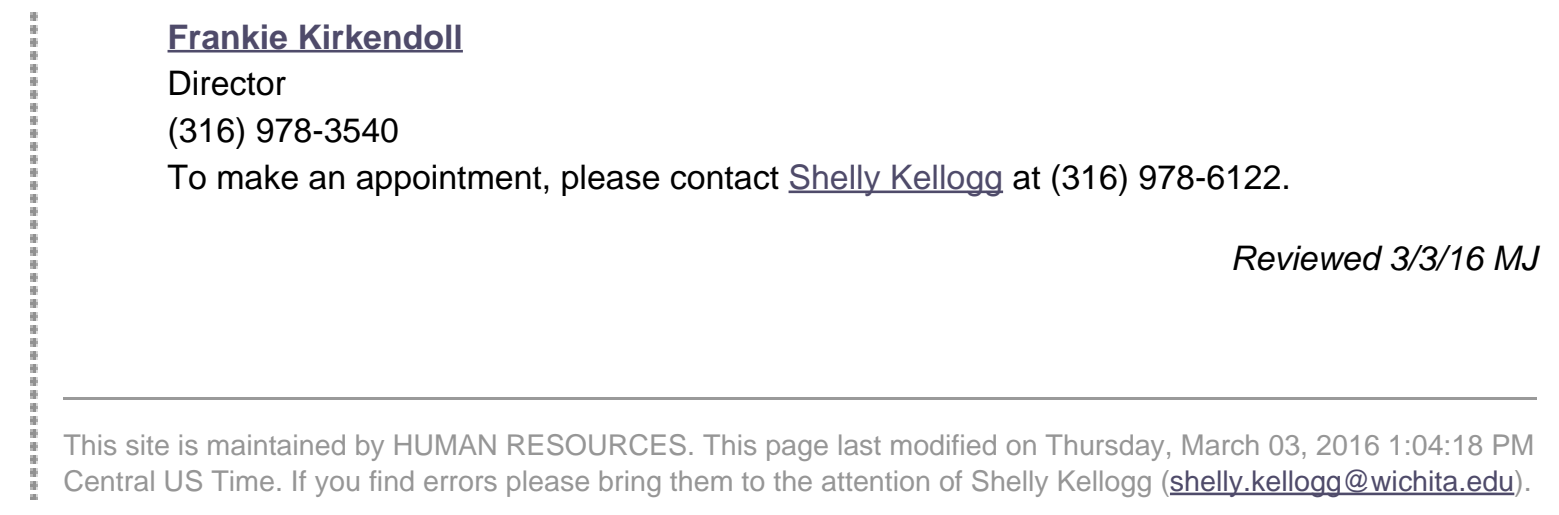

\section{Wichita State University | 1845 Fairmount St. Wichita, Kansas 67260 | (316) 978-3456}

A-Z | Policies and Procedures | Notice of Nondiscrimination | Campus Safety | RSS Feeds | Contact Wichita State University

(C) 1995-2016 Wichita State University. All rights reserved.

Select Language

Powered by Google Translate 


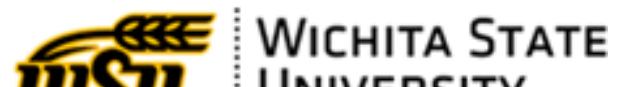 UIS UNIVERSITY}

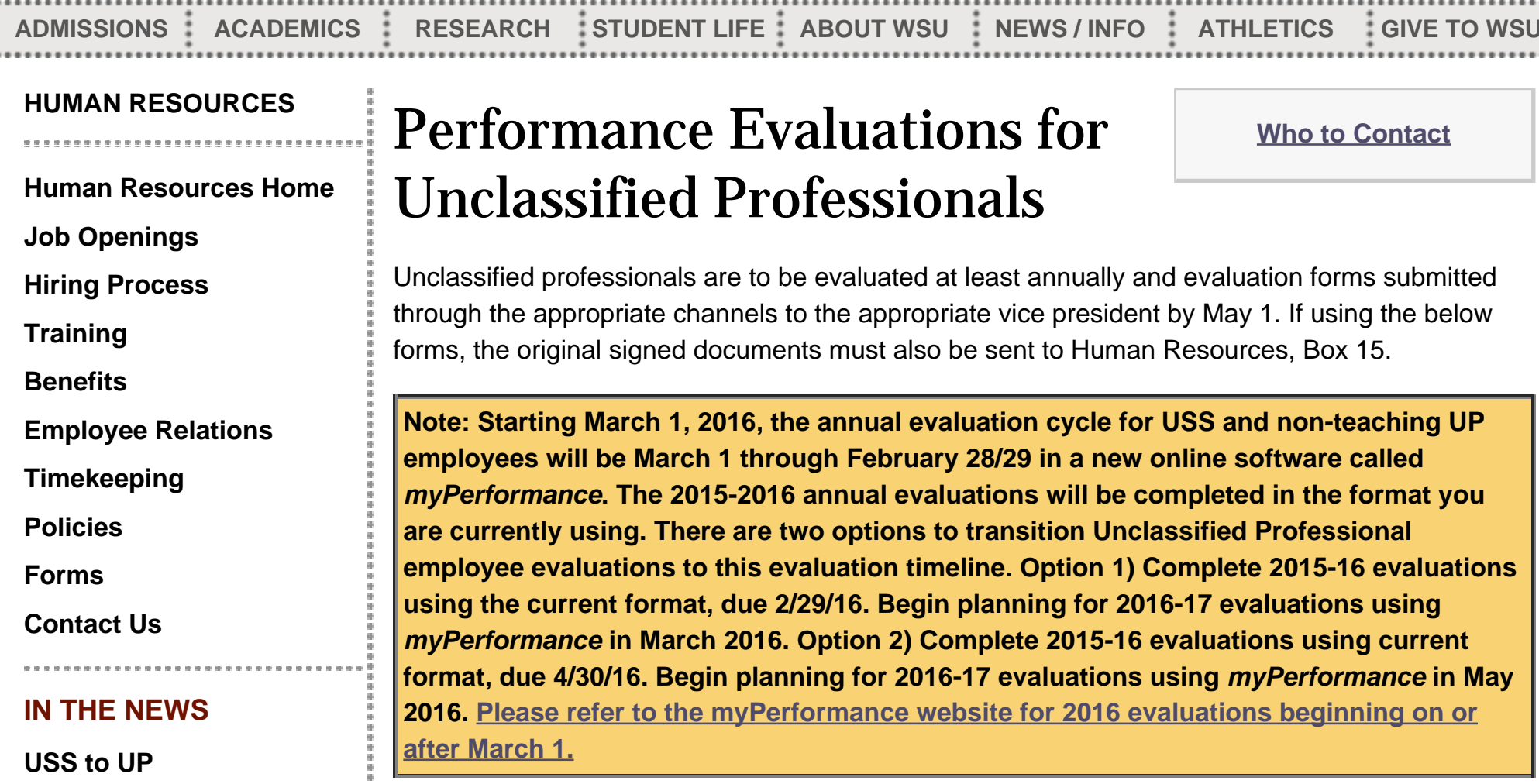

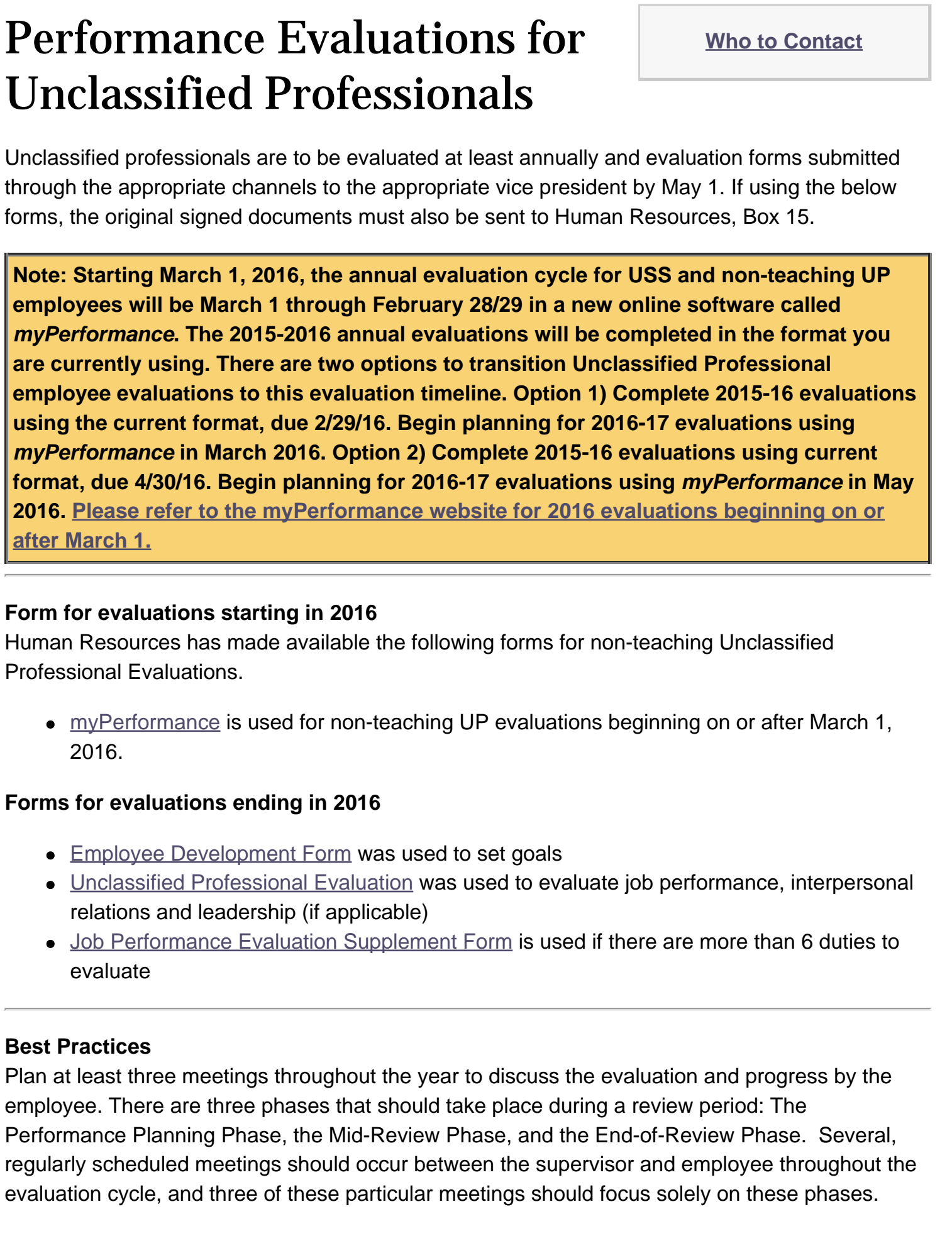

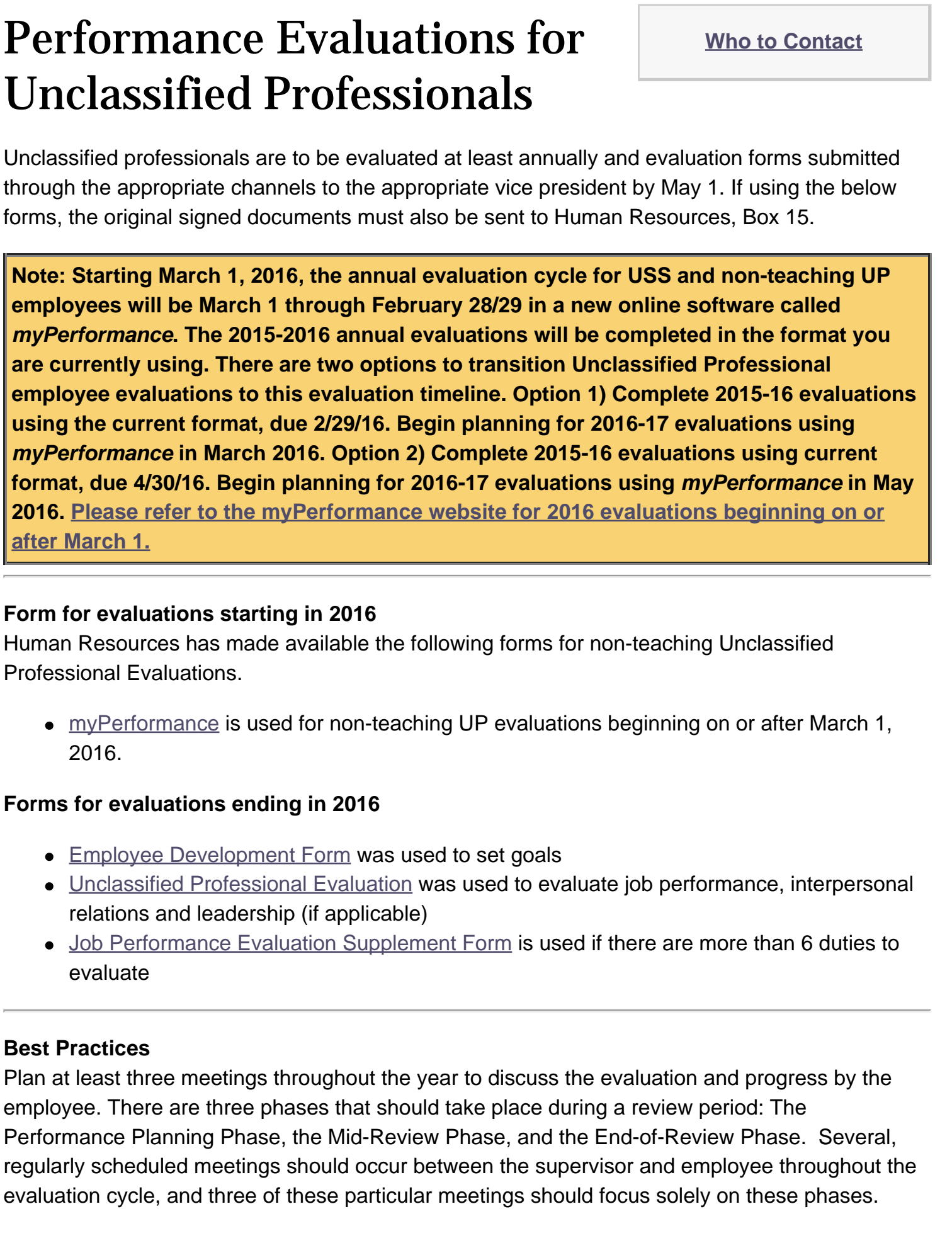

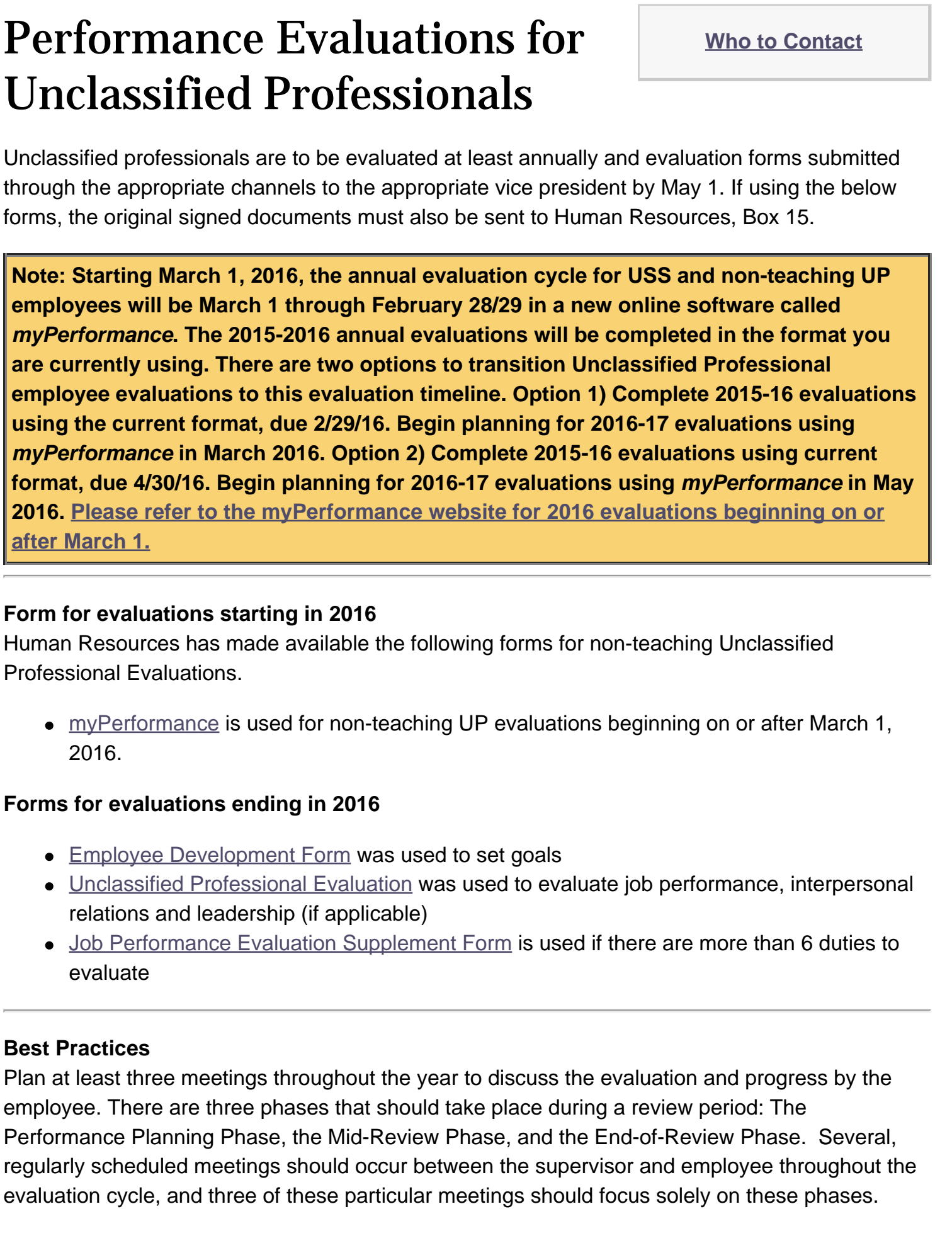

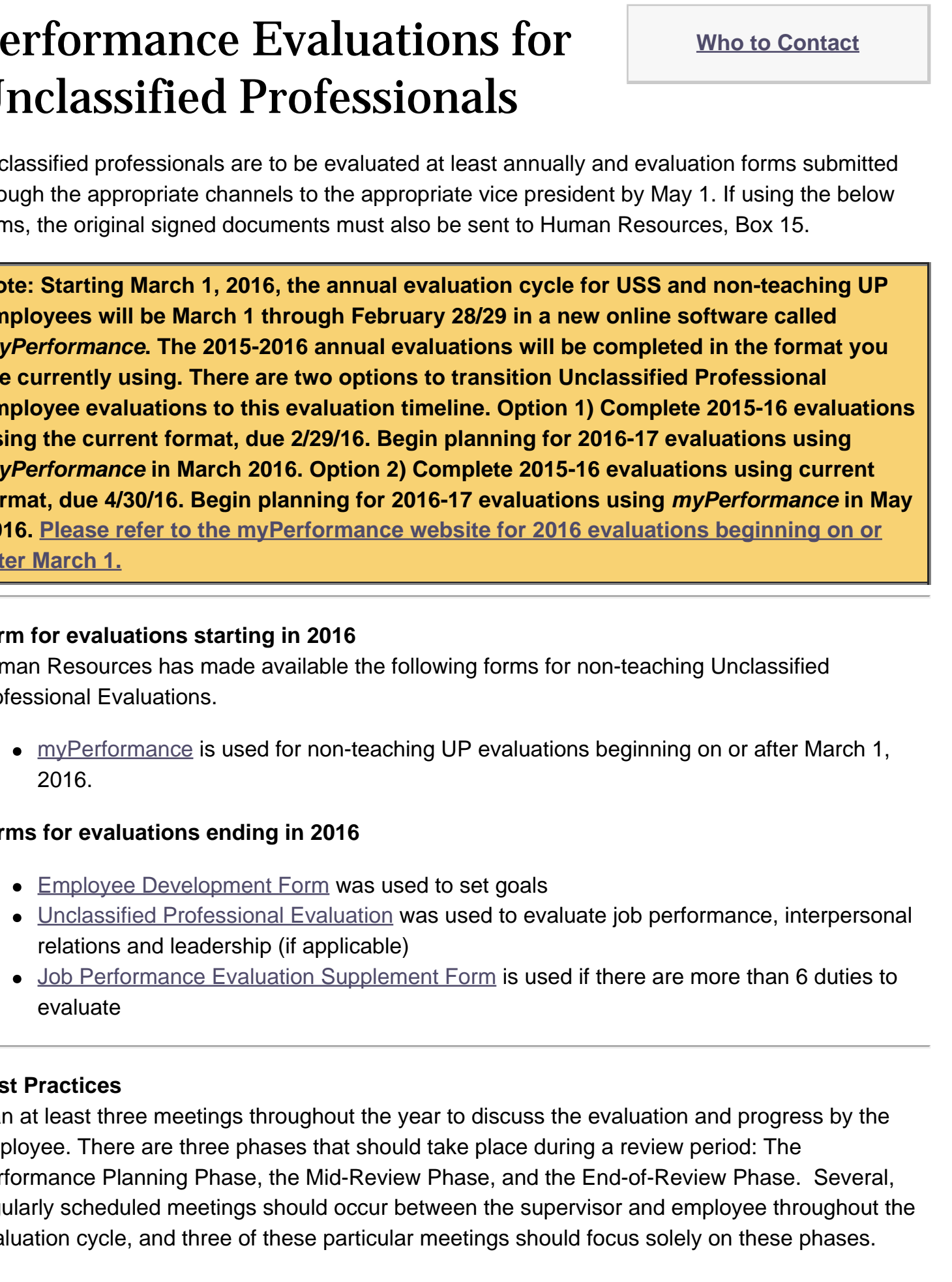

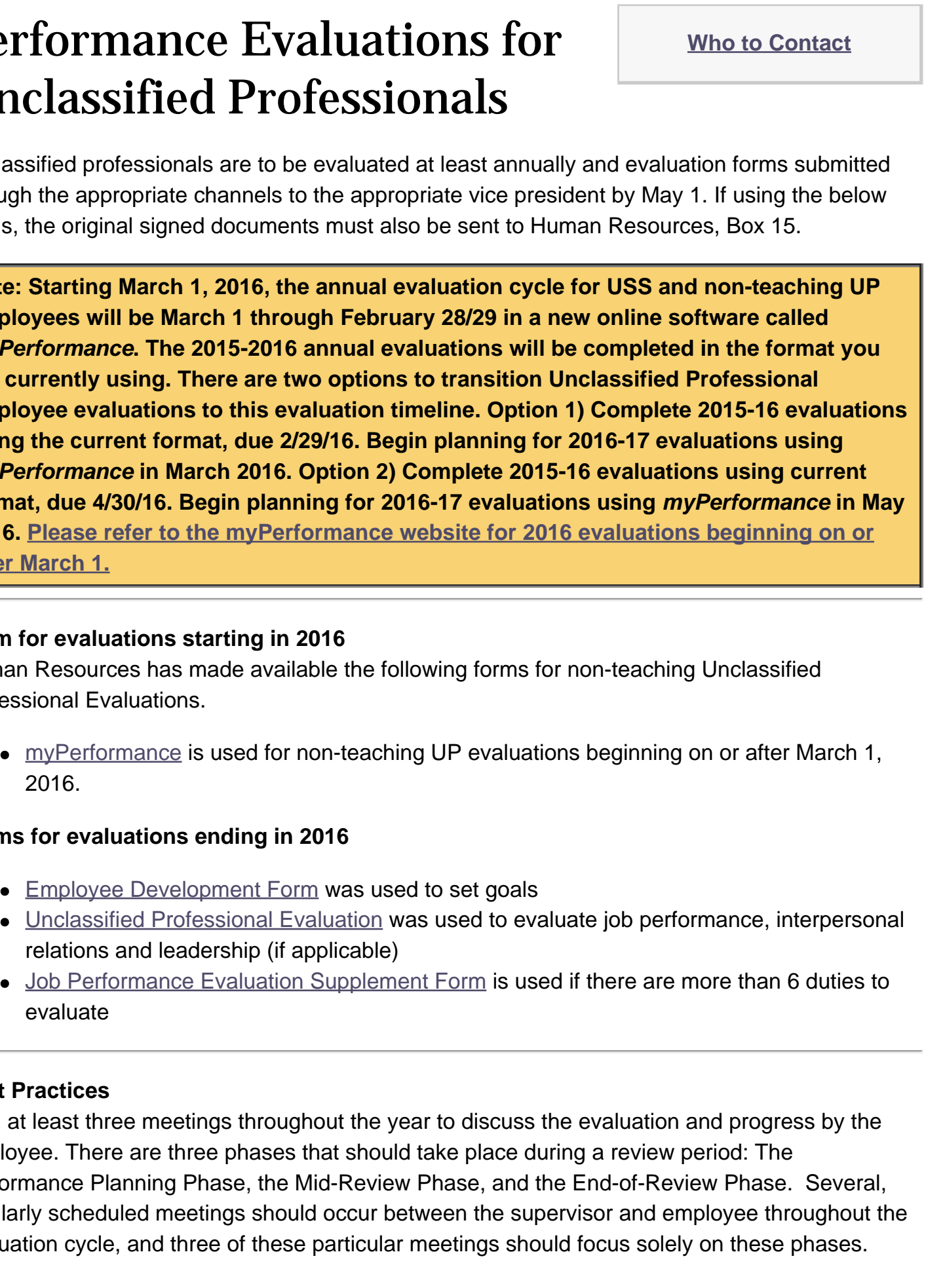

Office of Human Resources

1845 Fairmount

Box 15

Wichita, KS 67260-0015

316-978-3065

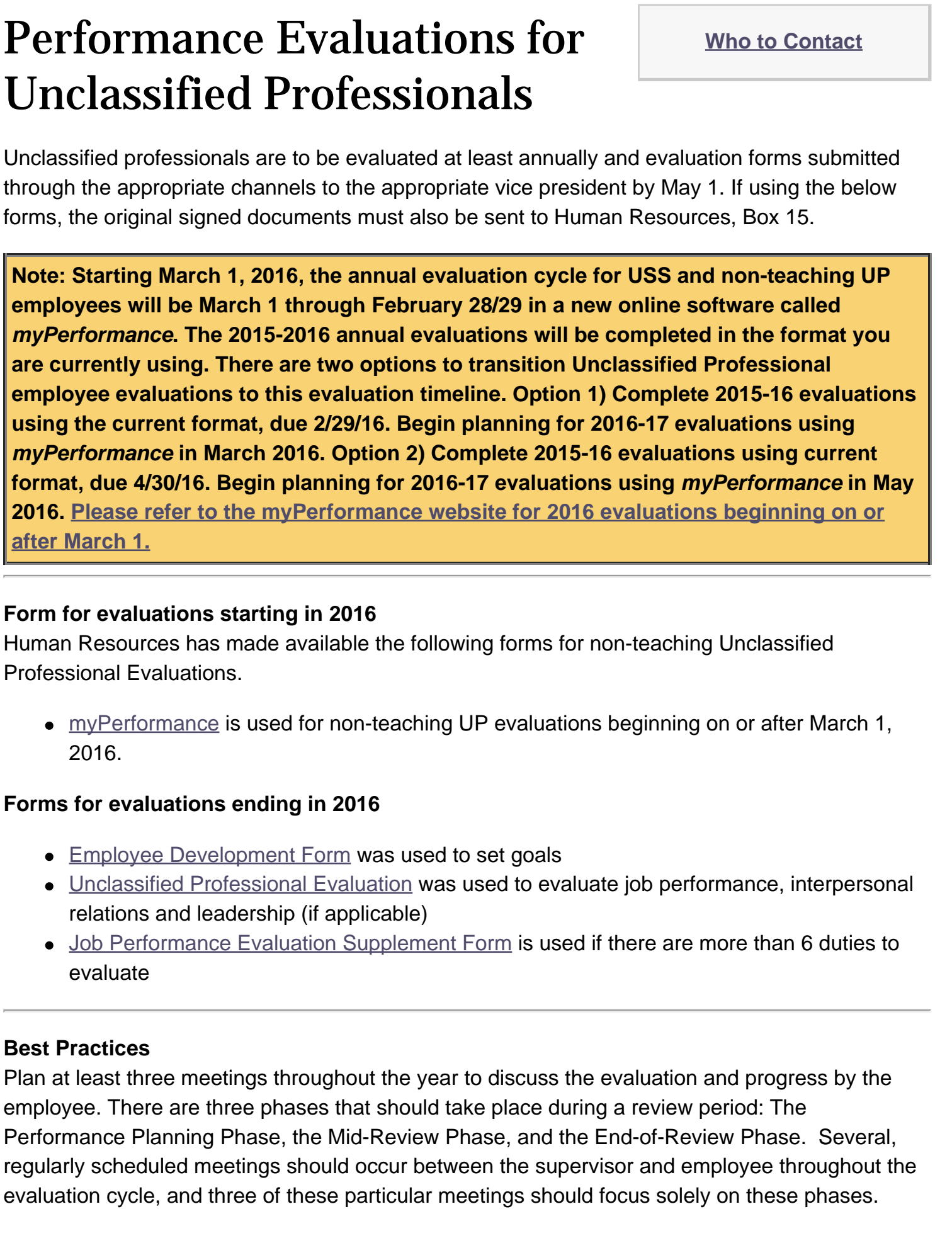

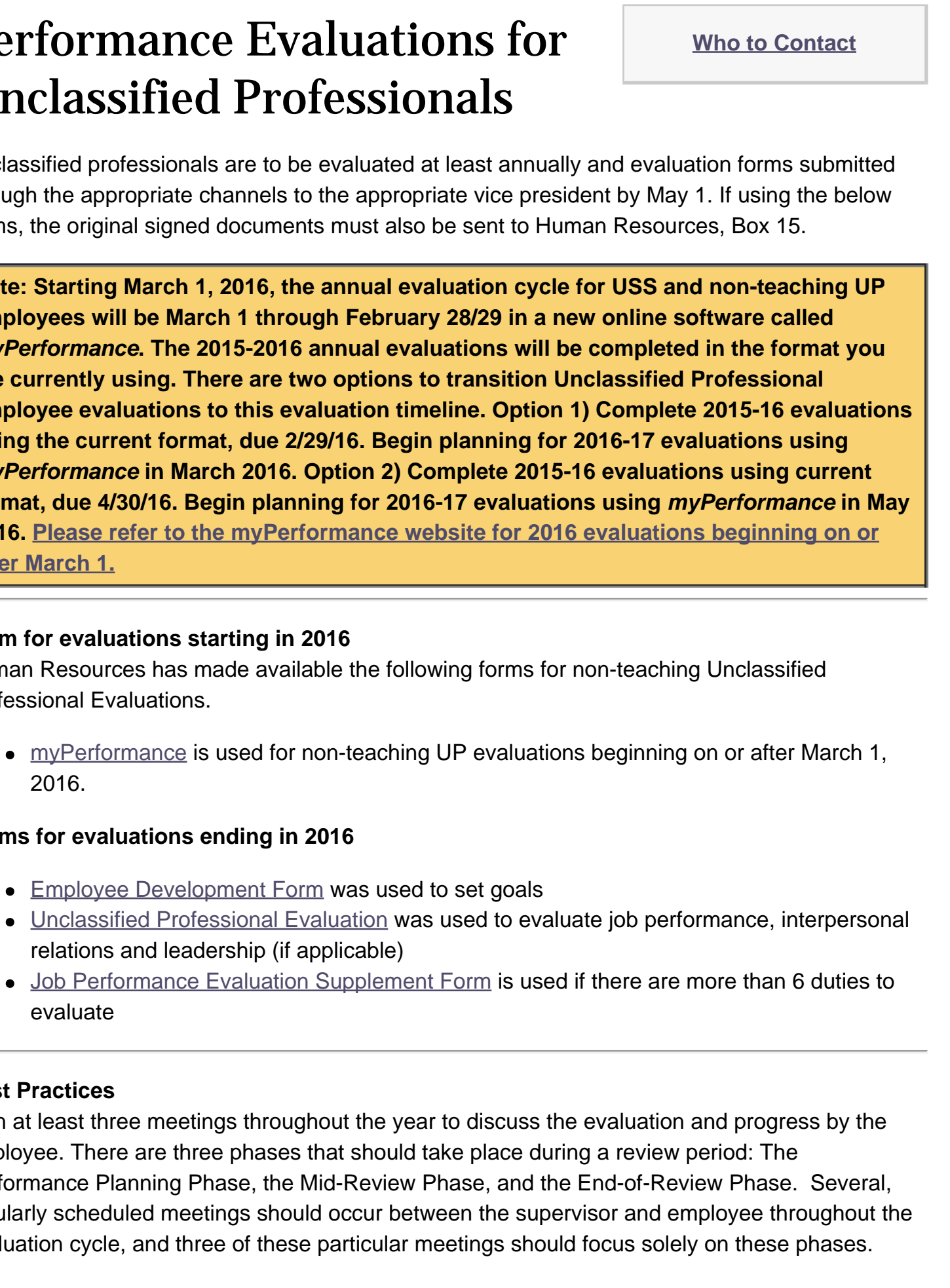

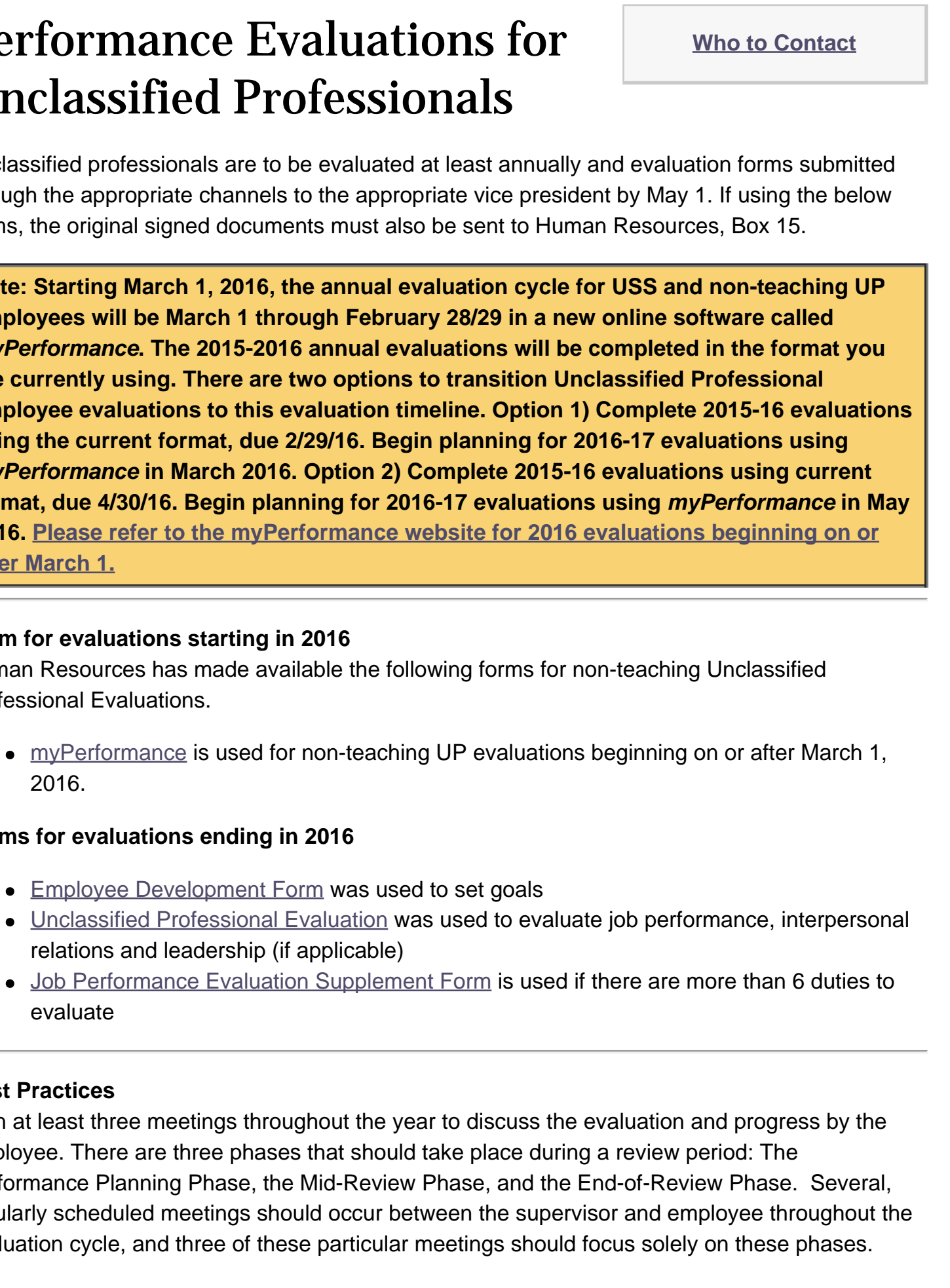

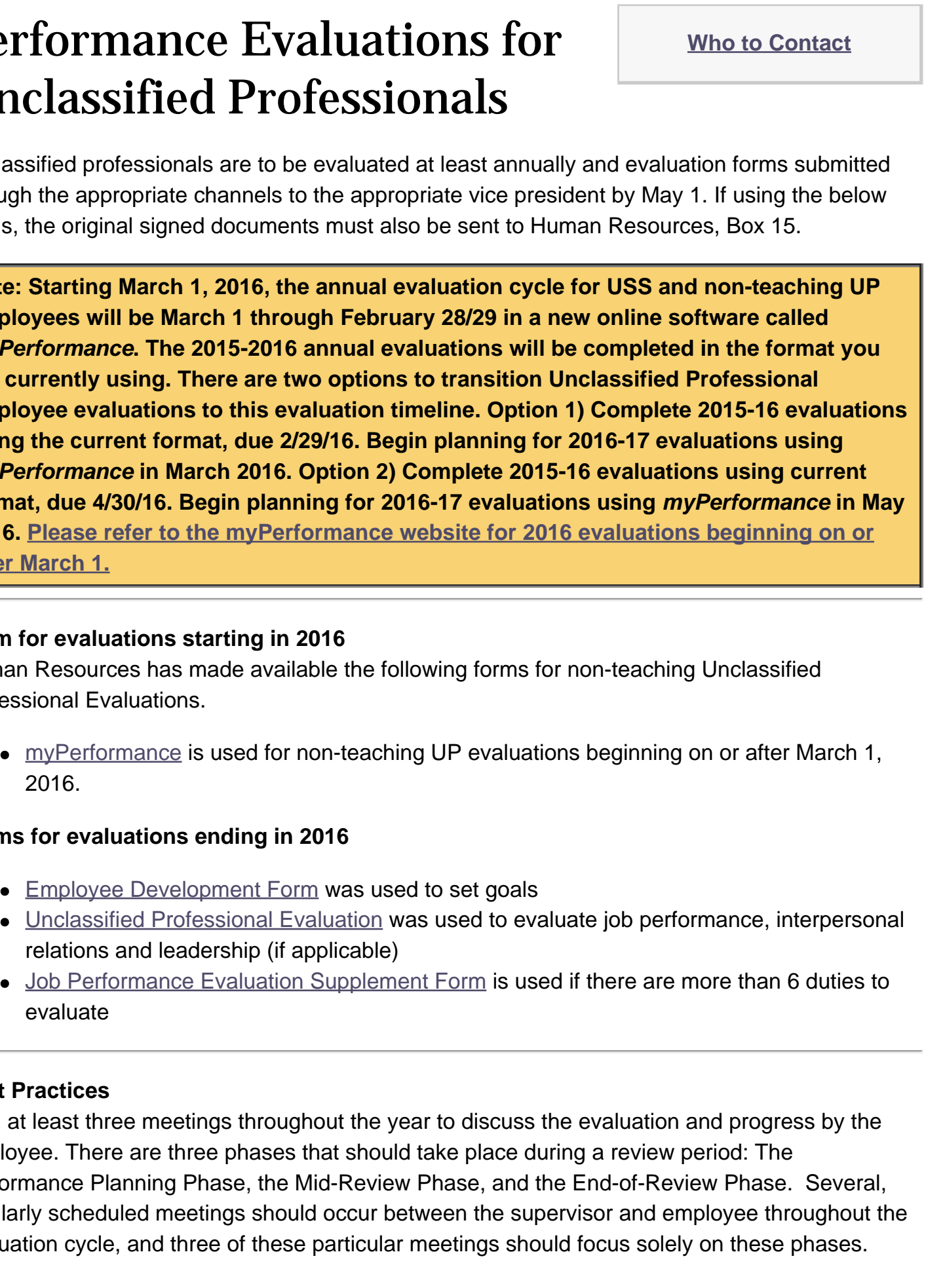

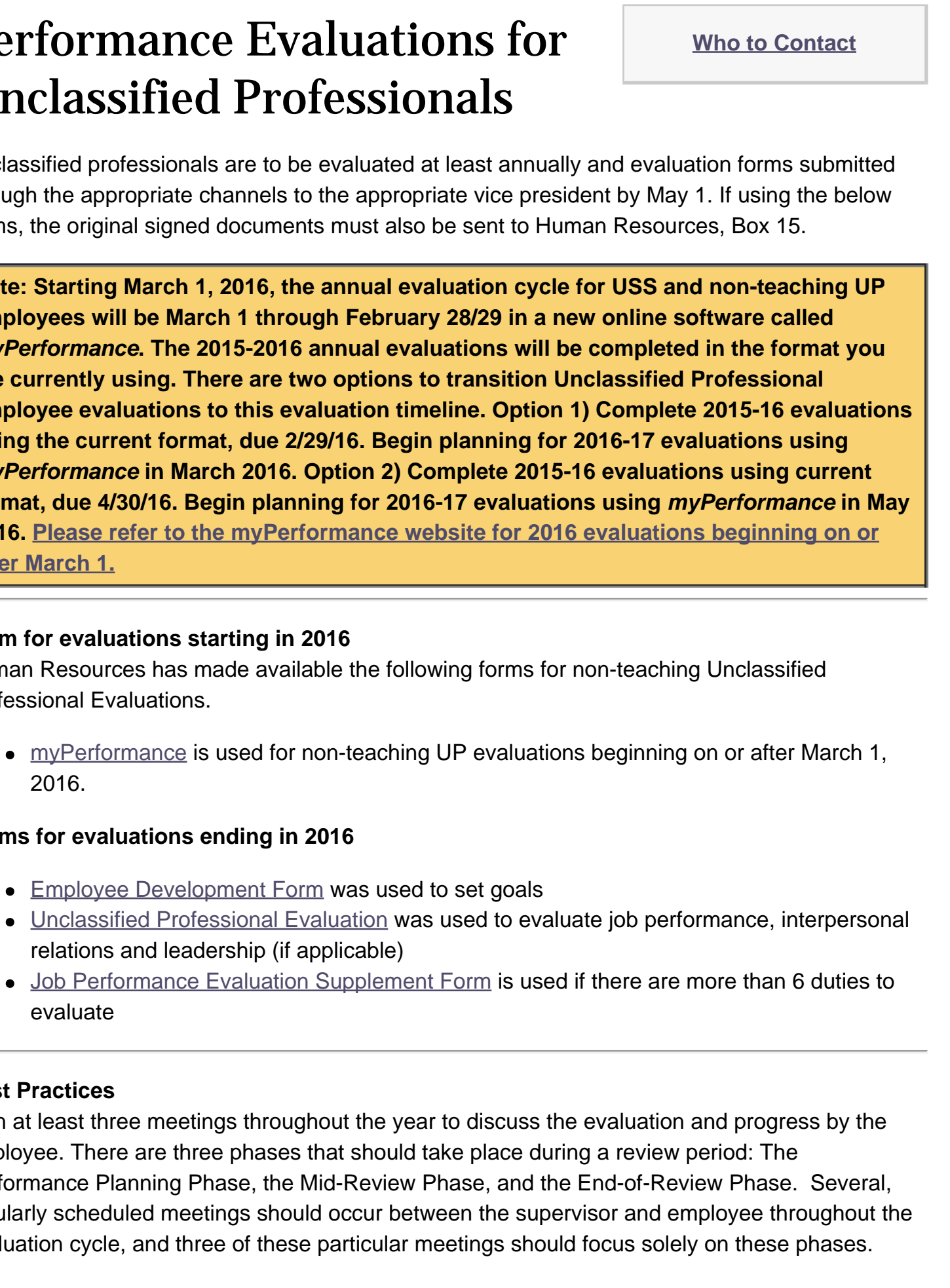

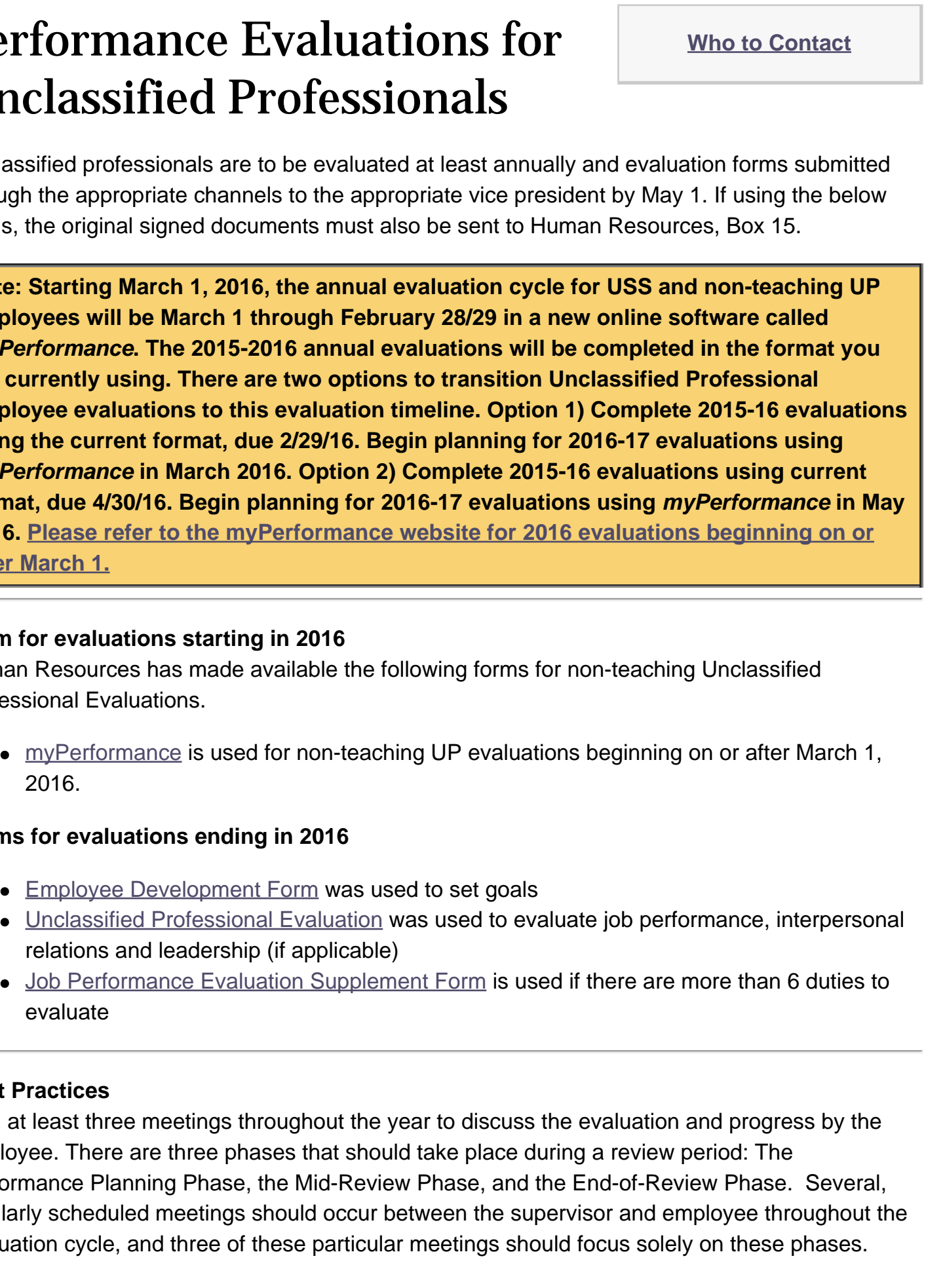

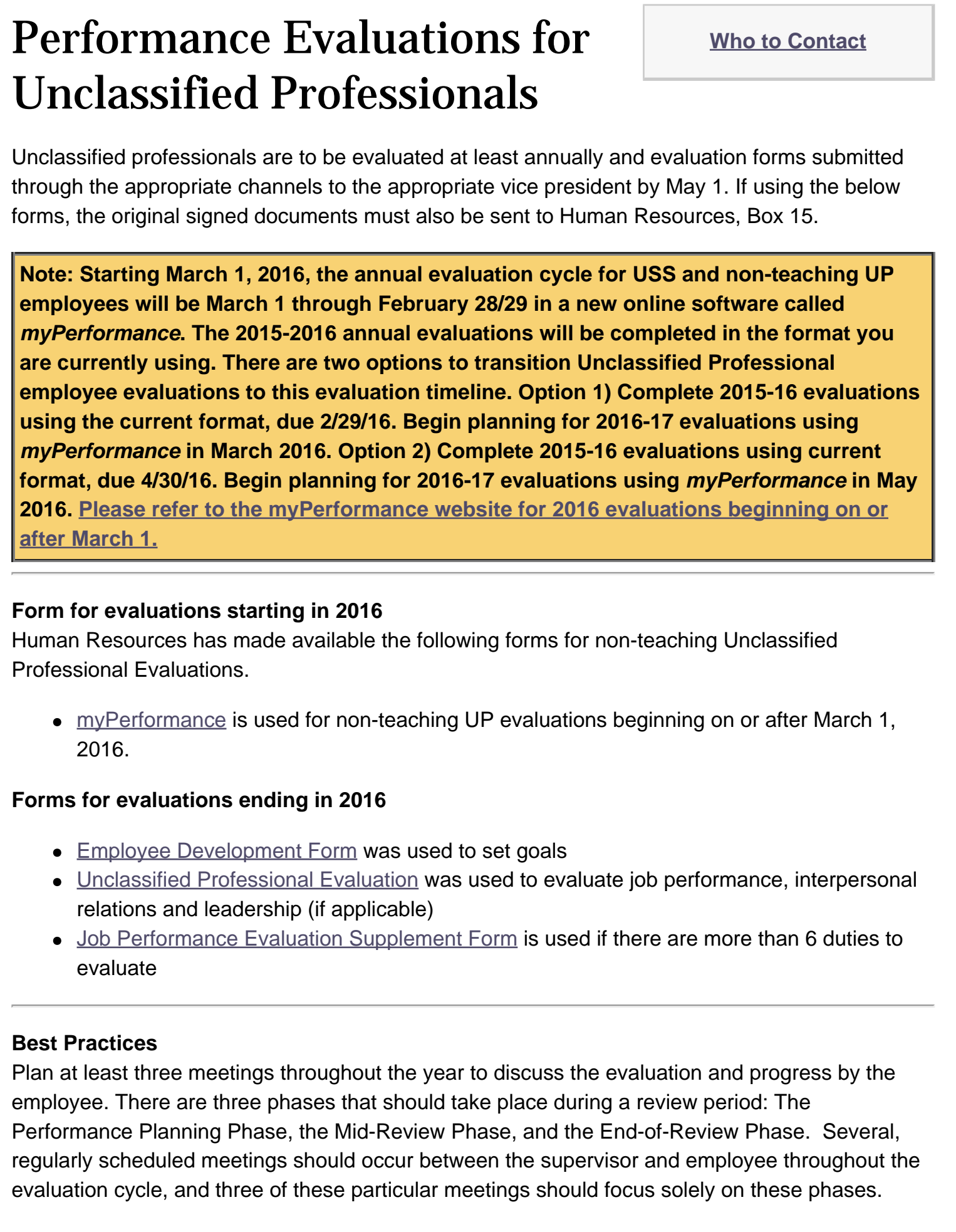

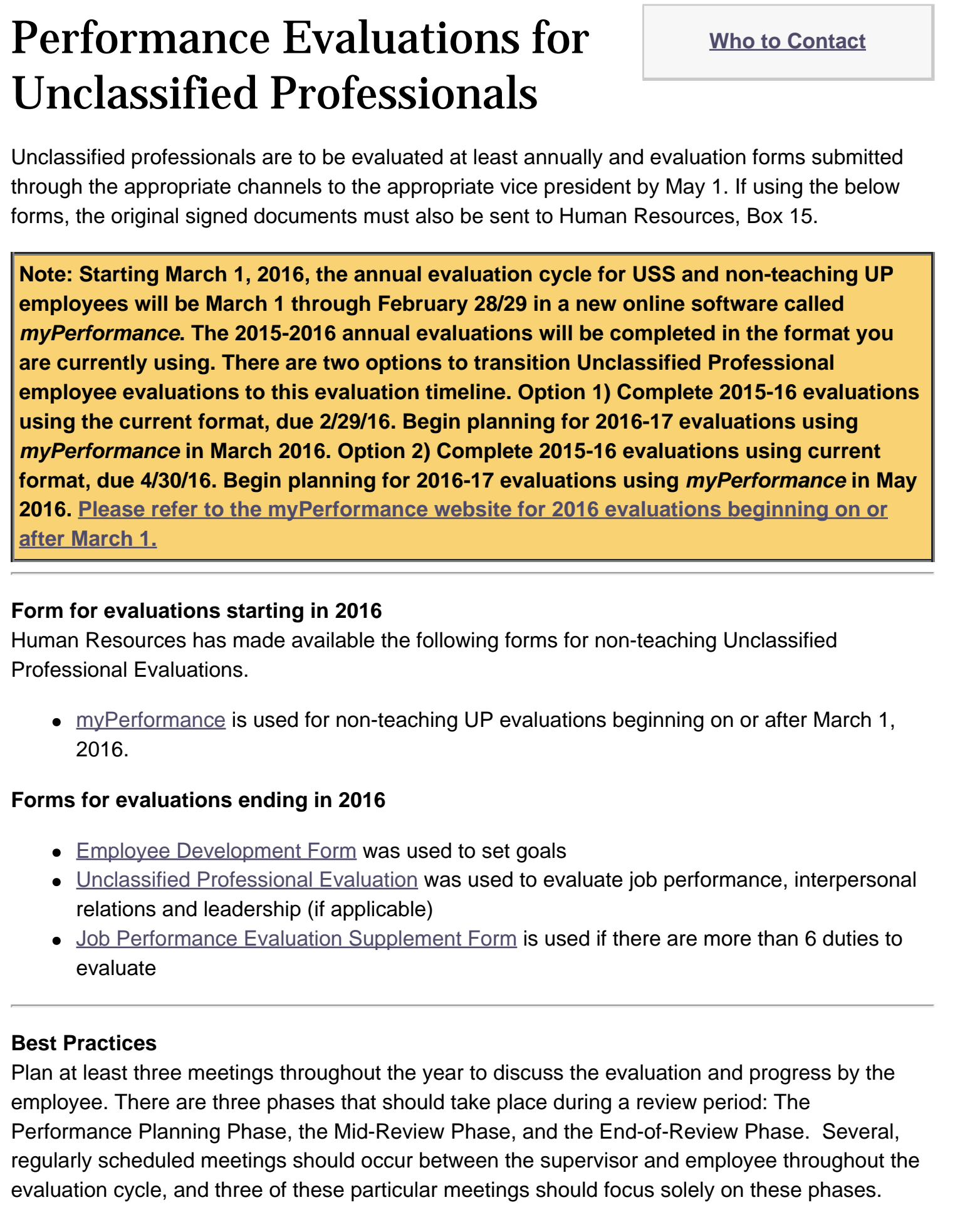

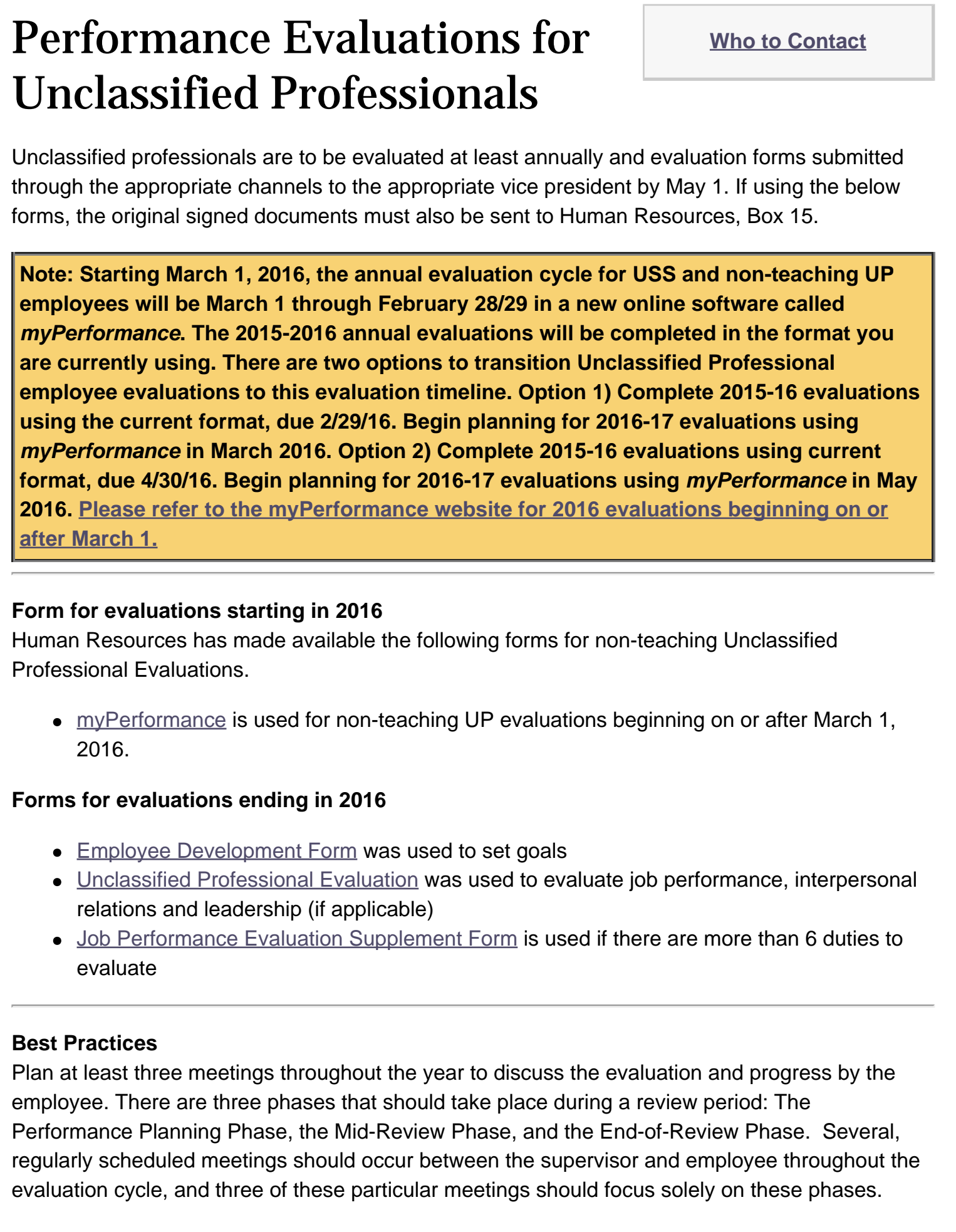

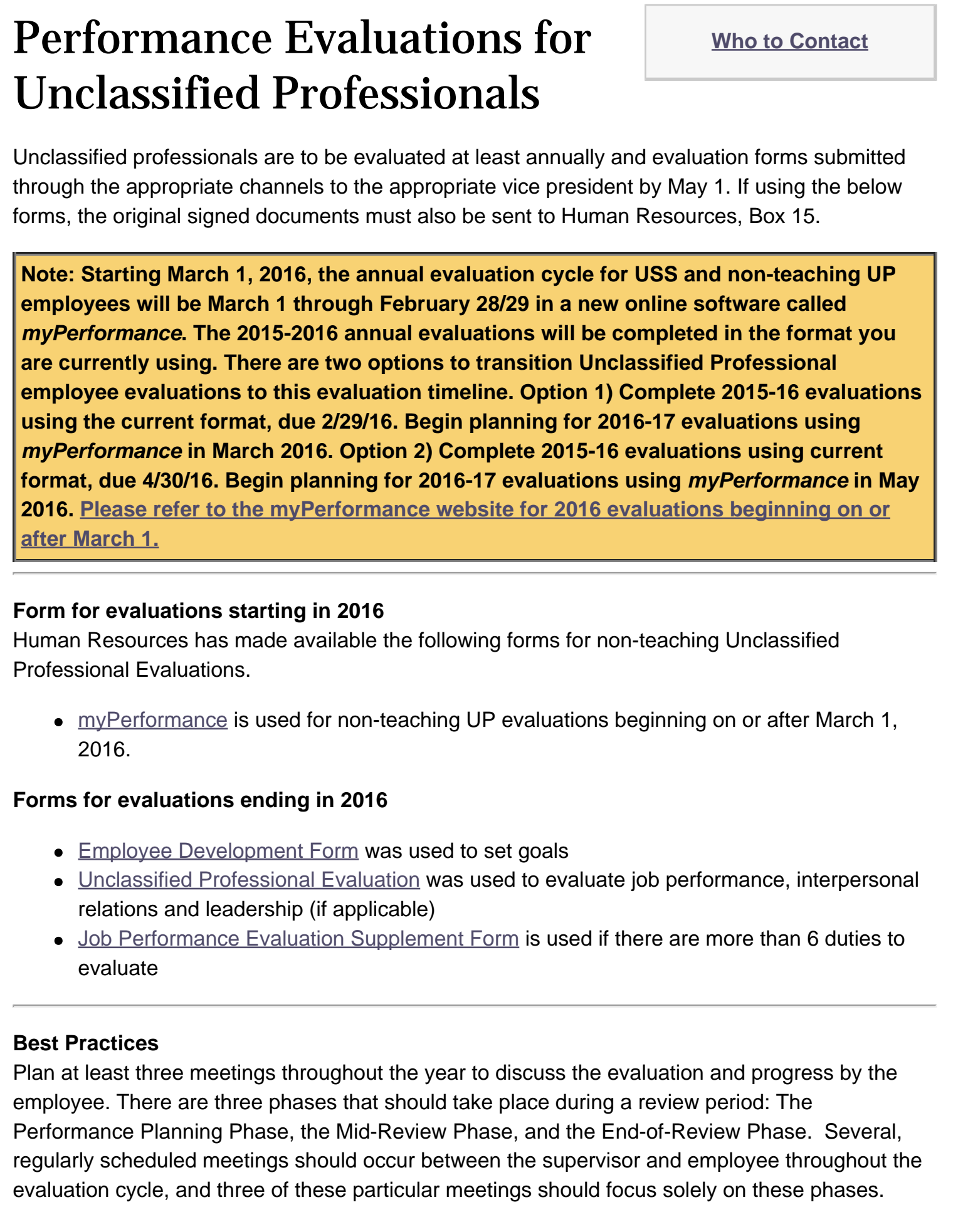

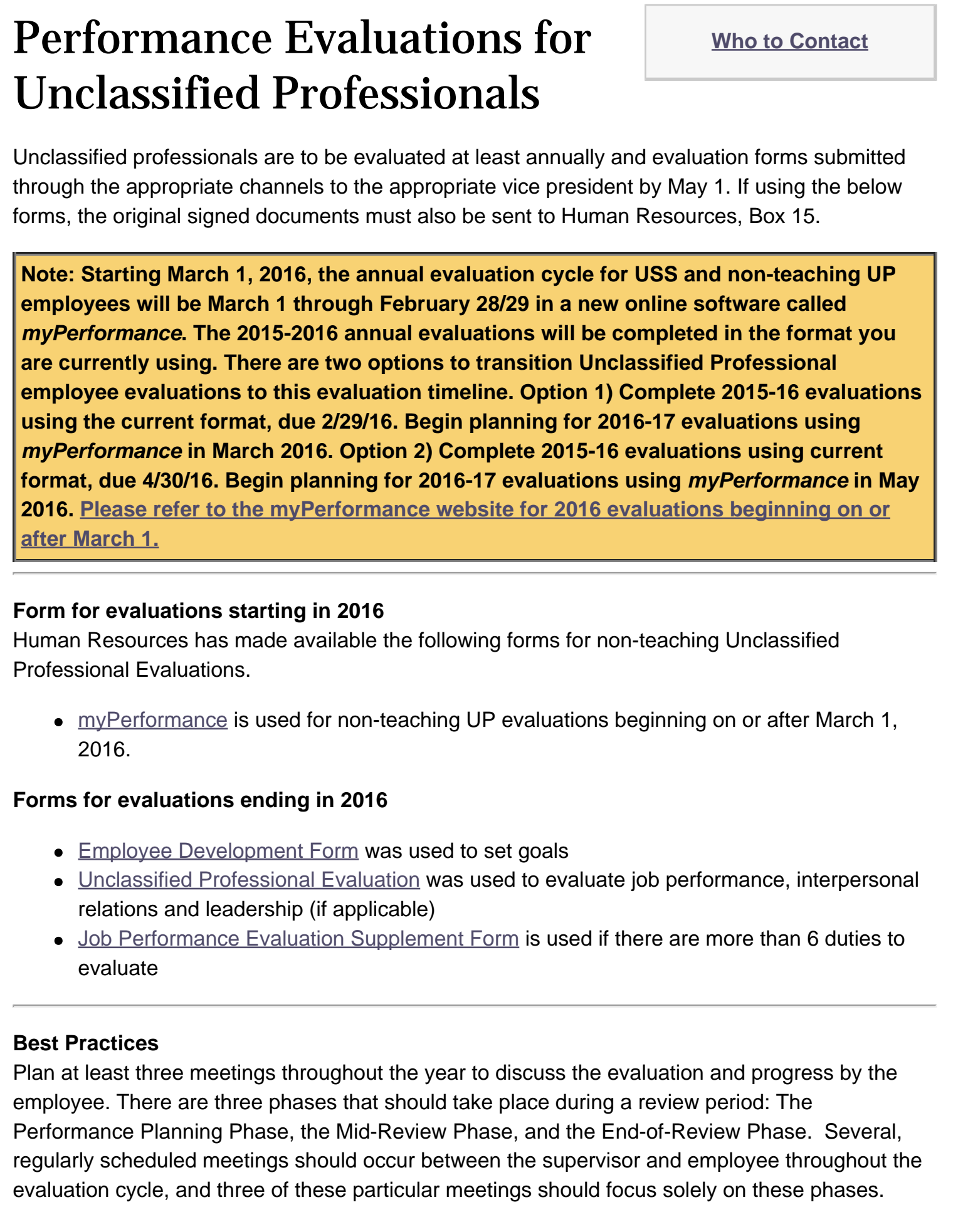

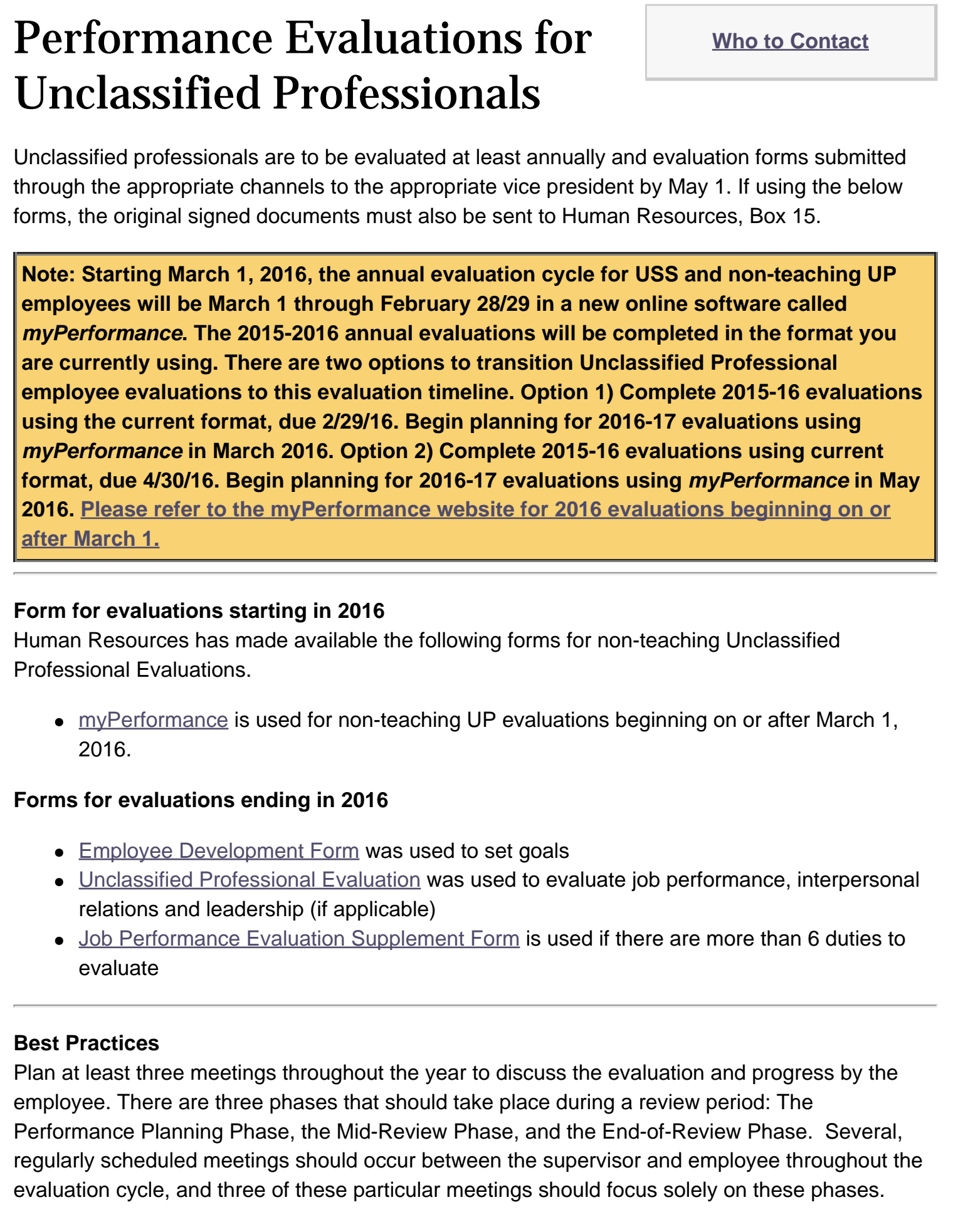

- The Performance Planning Phase should be completed within the first 30 days of the cycle to set objectives and expectations for the employee and collect the employee's signature on those objectives.

- The Mid-Review Phase should be completed half way through the evaluation cycle to 
discuss the employee's progress towards the goals, the need to amend any of the goals, and to collect the employee's signature for the amended evaluation.

- The End-of-Review Phase should be completed and submitted to Human Resources on or before the end of review date. This includes sending a signed copy of the full evaluation to Campus Box \#15 by the end of the review period. The signed copy should include signatures from all 3 phases described above.

- Make a copy of the evaluation for the supervisor and the employee.

If the evaluation is for an Unclassified Professional who teaches, please go to the Academic Affairs website for the proper form.

\section{Who to contact:}

Matthew Johnston

Associate Director

(316) 978-6123

To make an appointment, please contact LaMar Brown at (316) 978-3068.

\section{Frankie Kirkendoll}

Director

(316) 978-3540

To make an appointment, please contact Shelly Kellogg at (316) 978-6122.

\section{Wichita State University | 1845 Fairmount St. Wichita, Kansas 67260 | (316) 978-3456}

A-Z | Policies and Procedures | Notice of Nondiscrimination | Campus Safety | RSS Feeds | Contact Wichita State University (C) 1995-2016 Wichita State University. All rights reserved.

\section{Select Language}

Powered by Google Translate 


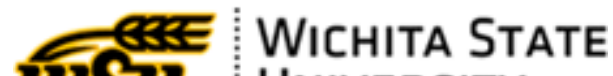 \\ MSSU UNIVERSITY}

Job Openings

Hiring Process

Training

Benefits

Employee Relations

Timekeeping

Policies

\section{Forms}

\section{Contact Us}

\section{IN THE NEWS}

\section{USS to UP \\ Reclassification}

\section{Video of Market Study Campus Visit}

\section{Financial Counseling}

Office of Human Resources 1845 Fairmount

Box 15

Wichita, KS 67260-0015

316-978-3065
All faculty, with half-time or more appointments, and those unclassified professionals who have teaching responsibilities amounting to 50 percent or more of their workload, are to be evaluated at least once a year regardless of whether or not they are in the Academic Affairs division of the University, per Policy 4.22 in the Policies and Procedures Manual.

The Provost and Senior Vice President establishes procedures in consultation with the Faculty Senate for implementation of this policy. Further Faculty Evaluation information can be found under Policy 4.22 in the Policies and Procedures Manual.

\section{Forms}

The evaluation forms and deadlines can be found in the Office of the Provost and Senior Vice President.
This site is maintained by HUMAN RESOURCES. This page last modified on Thursday, August 21, 2014 10:28:20 AM Central US Time. If you find errors please bring them to the attention of Shelly Kellogg (shelly.kellogg@wichita.edu).

\section{Wichita State University | 1845 Fairmount St. Wichita, Kansas 67260 | (316) 978-3456}

A-Z | Policies and Procedures | Notice of Nondiscrimination | Campus Safety | RSS Feeds | Contact Wichita State University (c) 1995-2016 Wichita State University. All rights reserved.

Select Language

Powered by Google Translate 


\section{WichITA STATE \\ USTU UNIVERSITY}

\section{Human Resources Home}

Job Openings

Hiring Process

\section{Training}

\section{Benefits}

\section{Employee Relations}

\section{Timekeeping}

Policies

Forms

\section{Contact Us}

\section{IN THE NEWS}

\section{USS to UP \\ Reclassification}

\section{Video of Market Study Campus Visit}

\section{Financial Counseling}

Office of Human Resources 1845 Fairmount

Box 15

Wichita, KS 67260-0015

316-978-3065
Student Employees at WSU are not required to be evaluated on performance in any systematic way. Human Resources would recommend, however, that supervisors of student employees evaluate them on a regular basis.

\section{Forms}

The Unclassified Performance Evaluation can be used for student employees as an option.

Supervisors may download the form and its supplemental goal-setting form below.

- UP Performance Evaluation - Download in Word or Download in PDF

- Supplemental Goal Setting Form
This site is maintained by HUMAN RESOURCES. This page last modified on Thursday, March 26, 2015 11:09:02 AM Central US Time. If you find errors please bring them to the attention of Shelly Kellogg (shelly.kellogg@wichita.edu). 